\title{
Missense mutations and polymorphisms of the $M C 4 R$ gene in Polish obese children and adolescents in relation to the relative body mass index
}

\author{
Joanna Nowacka-Woszuk • Jakub Cieslak • \\ Bogda Skowronska • Katarzyna A. Majewska • \\ Witold Stankiewicz • Piotr Fichna • Marek Switonski
}

Received: 26 January 2011 /Revised: 8 February 2011 / Accepted: 15 February 2011 /Published online: 15 March 2011

(C) The Author(s) 2011. This article is published with open access at Springerlink.com

\begin{abstract}
Extensive studies of the $M C 4 R$ gene polymorphism showed that, among numerous variants, there are mutations responsible for monogenic obesity, as well as polymorphisms negatively correlated with the risk of obesity. In this report, we present the first studies of the whole coding sequence of the $M C 4 R$ gene in 243 Polish obese children and adolescents (the mean relative body mass index [RBMI] was 163.6). In addition, 101 non-obese adults were also analyzed. Direct sequencing facilitated the identification of six missense (K73R, V103I, T112M, S127L, M215L, and I251L) and one silent (c.756 C $>\mathrm{T}$ ) single-nucleotide polymorphisms (SNPs). Two non-synonymous polymorphisms (K73R and $\mathrm{M} 215 \mathrm{~L}$ ) appeared to be novel and one was found in obese patients (M215L, one patient) and one in non-obese adults (K73R, one person). The overall frequency of nonsynonymous variant carriers reached $4.1 \%$ and $6.9 \%$ in obese patients and non-obese adults, respectively. Only one obesity-associated variant $(127 \mathrm{~L})$ was found in two obese patients $(0.82 \%)$ and in two non-obese adults $(1.98 \%)$. The
\end{abstract}

\footnotetext{
J. Nowacka-Woszuk $\cdot$ J. Cieslak $\cdot$ M. Switonski $(\bowtie)$

Department of Genetics and Animal Breeding,

Poznan University of Life Sciences,

Wołyńska 33,

60-637 Poznan, Poland

e-mail: switonsk@jay.au.poznan.pl

B. Skowronska $\cdot$ K. A. Majewska $\cdot$ W. Stankiewicz $\cdot$ P. Fichna

Department of Pediatric Diabetes and Obesity,

Poznan University of Medical Sciences,

Poznan, Poland

K. A. Majewska

Department of Pediatric Nursing,

Poznan University of Medical Sciences,

Poznan, Poland
}

obesity-protecting variants (103I and 251L) appeared to be the most common in both groups: $3.3 \%$ and $4.0 \%$, respectively. It was also observed that the RBMI in obese children and adolescents carrying the minor variants did not differ significantly from the non-carriers; however, the expected trends for the associated and protecting variants were observed. We conclude that the contribution of the $M C 4 R$ gene variants to the pathogenesis of obesity in Polish children and adolescents is low.

Keywords Adolescents · Children · MC4R - Mutation · Obesity $\cdot$ Polish population $\cdot$ Polymorphism

\section{Introduction}

It is well known that the monogenic form of obesity is mainly caused by mutations of the $M C 4 R$ gene (Santini et al. 2009; Tao 2009). There are over 150 variants of this gene described, but their causality varies and, usually, they are classified into five classes, in relation to their molecular effects (Tao 2009): class 1, truncated receptor with a loss of function; class 2, intracellular retention of the receptor presenting normal length; class 3, altered binding function of the receptor; 4, ligand binds the receptor but signal transduction is altered; and type 5, lack of the deleterious effect or the effect was not yet studied. Interestingly, there are also two $M C 4 R$ variants which are negatively correlated with the risk of obesity (Stutzmann et al. 2007; Wang et al. 2010). These polymorphisms cause amino acid substitutions in codon 103 (valine $>$ isoleucine, V103I) and codon 251 (isoleucine $>$ leucine, $\mathrm{I} 251 \mathrm{~L}$ ).

The occurrence of the $M C 4 R$ gene mutations causing obesity was studied in different populations and different 
age groups (for a review, see Santini et al. 2009). It was found that, in patients with an early-onset obesity, the incidence of the carriers varies from less than $1 \%$ among the Italian and Belgian populations to over $5 \%$ in the UK population. A recent study of Belgian obese children revealed the presence of 11 mutations, including two novel ones, where the mutation carrier frequency was $5.6 \%$ (Beckers et al. 2010). In obese adults, the frequency falls within the range from less than $1 \%$ (United Kingdom, Japan, Germany, etc.) to 5\% (Switzerland). Obesity is a serious health problem also in Poland and the frequency of overweight and obesity in children and adolescents reaches $18.7 \%$ and $14.1 \%$ for boys and girls, respectively, with a significant increase among boys at younger ages if compared to the previous decade (Kułaga et al. 2010).

Taking into consideration the major role of the $M C 4 R$ gene mutations in the pathogenesis of monogenic obesity and the lack of knowledge on their distribution in the Polish population, we decided to search for variants in the coding sequence of this gene in a cohort of obese Polish children or adolescents. Moreover, a group of non-obese adults was also analyzed.

\section{Materials and methods}

\section{Patients}

Altogether, 344 blood samples (243 from obese subjects and 101 non-obese adults) were collected from patients of the Department of Pediatric Diabetes and Obesity, Poznan University of Medical Sciences, Poznan, Poland. Each patient was assigned to one of two groups: obese children and adolescents (relative body mass index $[\mathrm{RBMI}]>120$ ) or non-obese adults (body mass index $[\mathrm{BMI}]<25$ ) with no obesity episodes in their lifetime (healthy individuals, age range: 35-45 years). Unfortunately, a control group of non-obese children and adolescents was not included in this study and, thus, we assumed that non-obese adults may play, to some extent, a role as the control group. In the group of obese children and adolescents (119 girls and 124 boys), the following parameters were recorded: age, sex, total body mass, and height. The RBMI (relative BMI) was estimated by dividing the current BMI of every obese patient by the ideal (50th percentile) BMI for their age and gender and multiplying the obtained result by 100 (Cole et al. 2005). In the cohort of obese subjects (age range: 4-17 years, average age: $12.4 \pm 3.8$ years), the average RBMI was $163.6 \pm 22.9$. The study was approved by the local Bio-Ethics Committee at the Poznan University of Medical Sciences.
Methods

DNA was isolated from blood samples using a Blood Mini isolation kit (A\&A Biotechnology, Poland) according to the manufacturer's protocol. The coding region of the MC4R gene was polymerase chain reaction (PCR)-amplified as two fragments (536 and $708 \mathrm{bp}$, respectively). The PCR primers (MC4R1F: 5'atcaattcagggggacactg, MC4R1R: 5' ccaaccegcttaactgtcat, MC4R2F: 5'gtagctcettgcttgcatcc, MC4R2R: 5'acggaagagaaagctgttgc) were designed according to the reference sequence deposited in the GenBank (NC_000018.9) and generated with the use of the Primer3 tool (http://frodo.wi.mit.edu/primer3/). For both amplified fragments, the following PCR conditions were applied: $95^{\circ} \mathrm{C}$, 10 min (preliminary denaturation); 35 cycles of: denaturation $95^{\circ} \mathrm{C}, 30 \mathrm{~s}$, annealing $60^{\circ} \mathrm{C}, 30 \mathrm{~s}$, elongation $72^{\circ} \mathrm{C}, 30 \mathrm{~s}$, and $72^{\circ} \mathrm{C}, 10 \mathrm{~min}$ (final synthesis). PCR was run in a Biometra TGradient thermocycler (Biometra, Germany) using Allegro Taq polymerase (Novazym, Poland). Amplified fragments of the $M C 4 R$ gene were screened for polymorphisms using the direct sequencing method (ABI Prism 3130 automatic sequencer, Applied Biosystems, USA). For statistical analysis, the $\mathrm{R}$ package was applied (version 2.12.0) (http://www.r-project.org/).

Polymorphic variant frequencies between slim and obese subjects were compared with the use of Fisher's exact test. We also measured the significance of differences in the average RBMI values between obese carriers of various $M C 4 R$ variants versus non-carriers, using the Wilcoxon rank-sum test. The comparison was performed for each polymorphic variant, as well as for three variant groups: obesity-associated, obesity-protective, and variants with unknown or unclear function. The groups were formed according to the present knowledge on the variant functionality.

\section{Results}

Altogether, 17 carriers of the non-synonymous $M C 4 R$ gene variants were found in the studied cohort (Table 1). To our knowledge, among the six identified missense substitutions, two were novel, i.e., c.218A $>\mathrm{G}$ and c.643A $>\mathrm{T}$ (Fig. 1), causing $\mathrm{K} 73 \mathrm{R}$ and $\mathrm{M} 215 \mathrm{~L}$ amino acid substitutions, respectively. The other variants described in our study were already reported earlier in other populations. The effect of four known variants could be classified, according to Tao (2009), to the following classes: 2 (S127L) and 5 (V103I, $\mathrm{T} 112 \mathrm{M}$, and $\mathrm{I} 251 \mathrm{~L})$. Two novel variants (K73R and M215L) with unknown function represented class 5. In addition, one obese patient was a carrier of the synonymous polymorphism (c.756 C > T). 
Table 1 Distribution of non-synonymous $M C 4 R$ polymorphism carriers in obese Polish children and adolescents, in comparison with a group of non-obese adults

\begin{tabular}{|c|c|c|c|c|c|c|}
\hline $\mathrm{SNP}^{\mathrm{a}}$ & Codon change & $\begin{array}{l}\text { Amino acid } \\
\text { position }\end{array}$ & $\begin{array}{l}\text { Amino acid } \\
\text { change }\end{array}$ & Variant class ${ }^{\mathrm{b}}$ & $\begin{array}{l}\text { Obese subjects } \\
(n=243)\end{array}$ & $\begin{array}{l}\text { Non-obese adults } \\
(n=101)\end{array}$ \\
\hline c. $218 \mathrm{~A}>\mathrm{G}$ & $\mathrm{AAG}>\mathrm{AGG}$ & 73 & $\mathrm{~K}>\mathrm{R}$ & $\mathrm{uc}^{\mathrm{c}}$ & - & $1(0.99 \%)$ \\
\hline c. $307 \mathrm{G}>\mathrm{A}$ & GUC $>$ AUC & 103 & $V>I$ & 5 & $6(2.46 \%)$ & $3(2.97 \%)$ \\
\hline c. $335 \mathrm{C}>\mathrm{T}$ & $\mathrm{ACG}>\mathrm{AUG}$ & 112 & $\mathrm{~T}>\mathrm{M}$ & 5 & $1(0.41 \%)$ & $2(1.98 \%)$ \\
\hline c. $380 \mathrm{C}>\mathrm{T}$ & $\mathrm{UCG}>\mathrm{UUG}$ & 127 & $S>L$ & 2 & $2(0.82 \%)$ & $2(1.98 \%)$ \\
\hline c. $643 \mathrm{~A}>\mathrm{T}$ & AUG $>$ UUG & 215 & $\mathrm{M}>\mathrm{L}$ & $\mathrm{uc}^{\mathrm{c}}$ & $1(0.41 \%)$ & - \\
\hline c. $751 \mathrm{~A}>\mathrm{C}$ & AUU $>$ CUU & 251 & $\mathrm{I}>\mathrm{L}$ & 5 & $2(0.82 \%)$ & $1(0.99 \%)$ \\
\hline \multicolumn{5}{|l|}{ All variants } & $10 *(4.1 \%)$ & $7 * *(6.9 \%)$ \\
\hline \multicolumn{5}{|c|}{ Obesity-protective variants (103I and 251L) } & $8(3.3 \%)$ & $4(4.0 \%)$ \\
\hline \multicolumn{5}{|c|}{ Obesity-associated variant (127L) } & $2(0.82 \%)$ & $2(1.98 \%)$ \\
\hline \multicolumn{5}{|c|}{ Neutral variants or variants with unknown effect $(73 \mathrm{R}, 112 \mathrm{M}$, and $215 \mathrm{~L})$} & $2(0.82 \%)$ & $3(2.97 \%)$ \\
\hline
\end{tabular}

${ }^{a}$ Also, one silent substitution c.756 C $>$ T was identified in an obese subject;

${ }^{\mathrm{b}}$ According to Tao (2009)

${ }^{\mathrm{c}}$ Unclassified

*Two patients carried two SNPs (103I and 127L)

${ }^{* *}$ Two adults carried two SNPs (103I and 127L)

A comparison of variant carriers in obese versus nonobese subjects did not show any significant differences (Table 1). However, the observed frequency tendencies appeared to be unexpected in case of some variants. When all of the non-synonymous variants were considered, the frequency of the carriers among the obese subjects was lower $(4.1 \%)$ than in the controls $(6.9 \%)$. Among the identified substitutions, only one variant $(127 \mathrm{~L})$ was associated with obesity. The frequency of its carriers was lower among obese patients $(0.82 \%)$ than in the control subjects $(1.92 \%)$. The V103I polymorphism was the most widely distributed and the incidence of the obesityprotective variant (103I) carriers was only slightly smaller
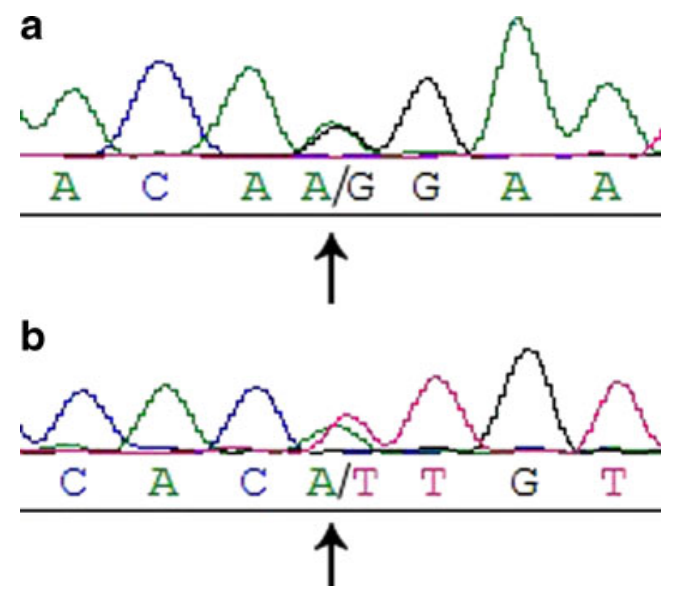

Fig. 1 Novel variants of the $M C 4 R$ gene causing amino acid substitutions: a c. $218 \mathrm{~A}>\mathrm{G}, \mathrm{K} 73 \mathrm{R}$; b c.643A $>\mathrm{T}$, M215L in the obese patients $(2.46 \%)$ than in non-obese adults $(2.97 \%)$. A similar trend was recorded for the other variant protecting against obesity (251L), found in $0.82 \%$ of obese subjects and $0.99 \%$ of non-obese adults. Two obese patients were carriers of two polymorphic variants, the obesityassociated (127L) and obesity-protective (103I) ones.

The RBMI in obese subjects $(n=243)$ was 163.6. We compared this parameter among the carriers $(n=10)$ and non-carriers $(n=233)$ for the identified variants (Table 2). The differences were not significant; however, some tendencies were observed. In case of the obesity-associated variant (127L), a higher mean RBMI was observed in the carriers $(177.5, n=2)$ than in the non-carriers $(163.5, n=241)$. A comparison of the obesity-protective variants (103I and 251L) revealed lower RBMI in the carriers $(159.7, n=8)$ than in the non-carriers $(163.7, n=235)$. Two carriers of the neutral variant $(112 \mathrm{M})$ or variant with unknown effect (215L) had slightly higher mean RBMI $(166.5, n=2)$ than the non-carriers $(163.6, n=241)$.

\section{Discussion}

Our main concern was focused on variants causing or associated with obesity. We found only one such variant $(127 \mathrm{~L})$ which affects the function of the encoded receptor. Two carriers of this variant, found in the studied cohort of obese patients, showed that their mean RBMI was higher than in non-carriers, as one could expect, but the difference was not significant. Functional analysis of the $127 \mathrm{~L}$ variant 
Table 2 A comparison of the RBMI in obese carriers of the $M C 4 R$ variants and in obese non-carriers

*Two patients carried two SNPs (103I and 127L)

\begin{tabular}{|c|c|c|c|c|}
\hline \multirow[t]{2}{*}{$M C 4 R$ minor variant and its effect on obesity } & \multicolumn{2}{|c|}{ Obese carriers } & \multicolumn{2}{|c|}{ Obese non-carriers } \\
\hline & $n$ & RBMI & $n$ & RBMI \\
\hline 127L: obesity-associated & $2^{*}$ & 177.5 & 241 & 163.5 \\
\hline 103I: obesity-protective & $6^{*}$ & 163.9 & 237 & 163.6 \\
\hline 251L: obesity-protective & 2 & 147.0 & 241 & 163.7 \\
\hline Total: obesity-protective & 8 & 159.7 & 235 & 163.7 \\
\hline 112M: neutral & 1 & 167.0 & 242 & 163.6 \\
\hline 73R: unknown & 0 & - & 243 & 163.6 \\
\hline 215L: unknown & 1 & 166.0 & 242 & 163.6 \\
\hline Total: neutral and unknown & 2 & 166.5 & 241 & 163.6 \\
\hline
\end{tabular}

was performed by Lubrano-Berthelier et al. (2003) and it was found that the encoded receptor demonstrates an impaired response to $\alpha$-MSH (a natural agonist for $M C 4 R$ ). However, the cell surface expression of the receptor was not altered. These authors also calculated that over $80 \%$ of all MC4R mutations associated with childhood obesity can be caused by the intracellular retention of the receptor. In our study, the frequency of this variant was lower in the obese patients $(0.82 \%)$ than in a group of 101 non-obese adults $(1.98 \%)$. However, it should be pointed out that the studied cohort of obese children and adolescents was rather small $(n=243)$. In another study, performed by Santoro et al. (2009), comprising a cohort of 240 obese Italian children, three obesity-associated mutations (S127L, Q307X, and Y332H) were found. The obesity variant $(127 \mathrm{~L})$ was found in three subjects $(1.25 \%)$, thus, the frequency was similar to our results. For these patients, also, their family members were investigated and it was shown that the mutation co-segregates with obesity. This mutation was also found in Czech obese children, but its frequency was very low $(0.34 \%)$, while the total frequency of the MC4R gene mutations in this cohort reached $2.4 \%$ (Hainerová et al. 2007).

We identified two novel missense substitutions (K73R and M215L). Unfortunately, we were not able to analyze the effect of these mutations on the receptor functionality. The variants were found in one obese patient $(215 \mathrm{~L})$ and in one non-obese adult (73R). Both amino acid substitutions are located in the cytoplasmatic topological domain and they do not change significantly the character of the amino acids. In the first mutation, arginine as well as lysine belong to the polar amino acids, while in the other mutation, methionine and leucine are the non-polar amino acids.

Two obesity-protective variants were the most frequently observed in both cohorts. This observation is in agreement with other studies. In a recent study of 291 obese Dutch children, 23 variants in the coding as well as $5^{\prime}$ flanking and 3' UTR sequences of the MC4R gene were identified (van den Berg et al. 2011). Six of them were localized in the $5^{\prime}$ flanking region (four in the $5^{\prime}$ UTR), 11 in the coding sequence, and two in the $3^{\prime}$ UTR. The minor allele frequency (MAF) ranged from 0.0017 to 0.35 . For the most common polymorphisms, considered as obesityprotective variants, V103I and $1251 \mathrm{~L}$, the MAF amounted to 0.01 (103I) and $0.0017(251 \mathrm{~L})$, respectively. In our study, the MAF values were similar: 0.013 for $103 \mathrm{~L}$ and 0.004 for $251 \mathrm{~L}$. A similar trend for the V103I polymorphism was obtained from the meta-analysis, where the frequency of the 103I variant carriers was $2.9 \%$ in obese $(n=19,882)$ and $3.9 \%$ in non-obese $(n=35,373)$ subjects (Wang et al. 2010). In that study, the authors gathered data from previously published papers and concluded that, among obese patients, the incidence of the 103I variant carriers varied from less than $0.1 \%$ (Italy) and $0.6 \%$ (Germany and Finland) to almost 20\% (Turkey). In nonobese subjects, the incidence of the carriers varied from $0 \%$ (Germany), $1 \%$ to $3.3 \%$ (Italy), $2.8 \%$ (Finland), up to $9 \%$ (Turkey). Recently, the V103I polymorphism was also studied in a cohort of 311 Polish adults (mean BMI=27) in relation to their physical activity (Jóźków et al. 2011). The incidence of the 103 I variant carriers was high $(6.4 \%)$ and, in addition, one patient $(0.3 \%)$ had a homozygous $103 \mathrm{I} /$ 103 I genotype. It was twofold higher than in the non-obese adults $(2.97 \%)$ and obese children and adolescents $(2.46 \%)$ described in our study. If the results presented in both reports were analyzed together $(n=343+311=654)$, the incidence of the carriers in the Polish population would be $4.43 \%$. Our study on the association between both variants and the RBMI showed that six carriers of the $103 \mathrm{~L}$ variant had a similar mean RBMI to that observed for noncarriers, while two carriers of the $251 \mathrm{~L}$ variant had a lower RBMI, but, again, the differences were not significant.

Recently, polymorphisms of other candidate genes for obesity were studied in the Polish population. Safranow et al. (2011) analyzed the distribution of mutations in the AMPD1 (adenosine monophosphate deaminase 1) gene in Polish patients with cardiovascular diseases and no significant associations between four studied polymorphic variants and the incidence of obesity (BMI $>30)$ were observed. Another study concerned polymorphisms in the $5^{\prime}$ flanking 
regions of three genes encoding adipokines: leptin, adiponectin, and resistin (Cieslak et al. 2011). The authors studied the same cohort of obese children and adolescents as in the present study. Altogether, 14 polymorphisms were detected and, among them, five were sufficiently distributed (minor allele frequency above 0.2 ) to study their association with the RBMI in obese children and adolescents, but none of them appeared to be associated.

Concluding, our results show for the first time the distribution of polymorphisms in the entire coding sequence of the MCAR gene in a cohort of Polish obese children and adolescents, as well as in a group of non-obese adults. Among the six identified non-synonymous variants, two (K73R and M215L) were considered as novel. The overall frequency of the missense variants in the obese patients was quite high $(4.1 \%)$, but not elevated when compared with the non-obese adults (6.9\%). We assume that the contribution of the $M C 4 R$ gene mutations and polymorphisms to the pathogenesis of obesity in Polish children and adolescents seems to be low.

Acknowledgment This study was financed by the Polish Ministry of Science and Higher Education, grant number: N407 057 32/2522.

Open Access This article is distributed under the terms of the Creative Commons Attribution Noncommercial License which permits any noncommercial use, distribution, and reproduction in any medium, provided the original author(s) and source are credited.

\section{References}

Beckers S, Zegers D, de Freitas F, Peeters AV, Verhulst SL, Massa G et al (2010) Identification and functional characterization of novel mutations in the melanocortin-4 receptor. Obes Facts 3:304-311

Cieslak J, Skorczyk A, Stachowiak M, Szydlowski M, Grzes M, Paczynska $P$ et al (2011) Polymorphisms in 5'-flanking regions of genes encoding adiponectin, leptin, and resistin are not associated with obesity of Polish children and adolescents. Mol Biol Rep 38:1793-1798

Cole TJ, Faith MS, Pietrobelli A, Heo M (2005) What is the best measure of adiposity change in growing children: BMI, BMI \%, BMI $z$-score or BMI centile? Eur J Clin Nutr 59:419-425

Hainerová I, Larsen LH, Holst B, Finková M, Hainer V, Lebl J et al (2007) Melanocortin 4 receptor mutations in obese Czech children: studies of prevalence, phenotype development, weight reduction response, and functional analysis. J Clin Endocrinol Metab 92:3689-3696

Jóźków P, Słowińska-Lisowska M, Laczmański L, Jakubiec D, Mędraś M (2011) Melanocortin-4 receptor gene polymorphism and the level of physical activity in men (HALS Study). Endocr 39:62-68. doi:10.1007/s12020-010-9412-7

Kułaga Z, Litwin M, Tkaczyk M, Palczewska I, Zajączkowska M, Zwolińska D et al (2010) Polish 2010 growth references for school-aged children and adolescents. Eur J Pediatr. doi:10.1007/ s00431-010-1329-x

Lubrano-Berthelier C, Durand E, Dubern B, Shapiro A, Dazin P, Weill $\mathrm{J}$ et al (2003) Intracellular retention is a common characteristic of childhood obesity-associated MC4R mutations. Hum Mol Genet $12: 145-153$

Safranow K, Suchy J, Jakubowska K, Olszewska M, Bińczak-Kuleta A, Kurzawski $\mathrm{G}$ et al (2011) AMPD1 gene mutations are associated with obesity and diabetes in Polish patients with cardiovascular diseases. J Appl Genet 52:67-76

Santini F, Maffei M, Pelosini C, Salvetti G, Scartabelli G, Pinchera A (2009) Melanocortin-4 receptor mutations in obesity. Adv Clin Chem 48:95-109

Santoro N, Cirillo G, Xiang Z, Tanas R, Greggio N, Morino G et al (2009) Prevalence of pathogenetic MC4R mutations in Italian children with early onset obesity, tall stature and familial history of obesity. BMC Med Genet 12:10-25. doi:10.1186/1471-2350-10-25

Stutzmann F, Vatin V, Cauchi S, Morandi A, Jouret B, Landt O et al (2007) Non-synonymous polymorphisms in melanocortin-4 receptor protect against obesity: the two facets of a Janus obesity gene. Hum Mol Genet 16:1837-1844

Tao YX (2009) Chapter 6 mutations in melanocortin-4 receptor and human obesity. Prog Mol Biol Transl Sci 88:173-204

van den Berg L, van Beekum O, Heutink P, Felius BA, van de Heijning MP, Strijbis S et al (2011) Melanocortin-4 receptor gene mutations in a Dutch cohort of obese children. Obesity (Silver Spring) 19:604-611. doi:10.1038/oby.2010.259

Wang D, Ma J, Zhang S, Hinney A, Hebebrand J, Wang Y et al (2010) Association of the MC4R V103I polymorphism with obesity: a Chinese case-control study and meta-analysis in 55,195 individuals. Obesity (Silver Spring) 18:573-579 